\title{
Specifically designed amine functional group doped sludge biochar for inorganic and organic arsenic removal
}

\author{
Chih-Kuei Chen ${ }^{1,2}$, Nhat-Thien Nguyen ${ }^{3 *}$ (D), Thuy-Trang Le ${ }^{4}$, Cong-Chinh Duong ${ }^{3,5}$ and Thi-Thanh Duong ${ }^{6}$
}

\begin{abstract}
Usages of hospital sludge as a biochar adsorbent for wastewater treatment plants were investigated. Microwave carbonization was used to carbonize the sludge and then chemically activated with $\mathrm{ZnCl}_{2}$ to increase surface area and porosity. A newly designed amine functional group's doped Sludge Biochar Carbon (SBC) presents effective inorganic arsenic (As (III)) and organic arsenic (Dimethylarsinic Acid, DMA) adsorption in water. The pore volume, pore size distribution and specific surface area were determined by performing nitrogen adsorption-desorption measurements. The Fourier Transform Infrared of the SBC was recorded to study the functional groups at room temperature. The composition of SBC was further determined by X-ray Photoelectron Spectroscopy. In order to understand the effect of amine functional complexes on arsenic adsorption, the adsorption mechanism of As (III) and DMA on SBC surfaces modified with amine functional complexes was studied using Density Functional Theory (DFT). DFT results showed that both physical and chemical adsorption of As (III) and DMA on SBC surfaces occurred. The participation of amine functional complexes greatly promoted the surface activity of SBC surface and its adsorption capacity on arsenic. The physical adsorption energies of As (III) and DMA on SBC surface with amine functional complexes were -38.8 and $-32.4 \mathrm{~kJ} \mathrm{~mol}^{-1}$, respectively. The chemical adsorption energies of As (III) and DMA on SBC surface with amine functional complexes were -92.9 and $-98.5 \mathrm{k} \mathrm{mol}^{-1}$, respectively.
\end{abstract}

Keywords: Hospital sludge, Biochar, As (III), DMA, Density functional theory

\section{Introduction}

Biochar has been identified as an effective adsorbent that can be used to remove various heavy metals dissolved in water, because the specific surface area and microporous structures of biochar are high. It hosts several surface functional groups, such as carboxyl $(-\mathrm{COOH})$, hydroxyl $(-\mathrm{OH})$ and amino $\left(-\mathrm{NH}_{2}\right)$, for adsorbing heavy metal effectively $[1,2]$. These groups can work through electron donation, cation exchange, electrostatic attraction, or surface complexation to effectively remove heavy metals [3]. Recent studies have focused on the use of many potential adsorbents: the utilization of sewage

\footnotetext{
* Correspondence: nguyennhatthien333@gmail.com

${ }^{3}$ Institute of Environmental Engineering and Management, National Taipei University of Technology, Taipei 10608, Taiwan

Full list of author information is available at the end of the article
}

sludge [4], waste tire rubber [5], natural lignocellulose materials [6], doum stone [7], clays and their minerals [8], agriculture and industrial waste [9] as cheap and environment friendly materials has attracted increasing attention [10]. An alternative carbon source is readily available in the form of hospital sludge, which is currently managed as a waste in Taiwan. The amount of hospital sludge in the country has steadily increased, thus forcing the government to spend a significant amount of money on managing this waste. According to the previous study, it needs to spend a lot of time, more than $24 \mathrm{~h}$, to prepare biochar from hospital sludge with traditional methods, such as pyrolysis and calcination with $\mathrm{N}_{2}$. It is important to shorten the time of preparing biochar within 15 min to get abundant products with feasible methods, such as microwave technology.

(c) The Author(s). 2021 Open Access This article is licensed under a Creative Commons Attribution 4.0 International License, which permits use, sharing, adaptation, distribution and reproduction in any medium or format, as long as you give

appropriate credit to the original author(s) and the source, provide a link to the Creative Commons licence, and indicate if changes were made. The images or other third party material in this article are included in the article's Creative Commons licence, unless indicated otherwise in a credit line to the material. If material is not included in the article's Creative Commons licence and your intended use is not permitted by statutory regulation or exceeds the permitted use, you will need to obtain permission directly from the copyright holder. To view a copy of this licence, visit http://creativecommons.org/licenses/by/4.0/. 
On the other hand, natural weathering processes, volcanic eruptions, gold mining, biological activity, burning of fossil fuels, smelting of metal ores, desiccants, wood preservatives and agricultural pesticides, and many other anthropogenic activities are responsible for the presence of arsenic in water [11]. Arsenic is toxic and induces hyper-pigmentation, muscle weakness, skin thickening, neurological disorders and human cancer. Drinking arsenic contaminated groundwater is the principal route of human exposure. Therefore, the arsenic level for drinking water has been established by the World Health Organization to $10 \mu \mathrm{g} \mathrm{L}^{-1}[12,13]$. In addition, As (III) is more toxic than $\mathrm{As}(\mathrm{V})$ since the former binds to single but with higher affinity for groups of sulfhydryls that associate with a variety of proteins and inhibit their activity and given its electronic structure, As (III) is more stable than $\mathrm{As}(\mathrm{V})$ [11].

Most ground state electronic structure calculations of molecules, atoms and solids are carried out using the Density Functional Theory (DFT) method. DFT is a valuable tool to study the mechanisms of interaction at the solid liquid interface. In the Zhang and Liu [14] research, DFT based quantum chemistry methods were used to explore the mechanism of adsorption of As (III) on the surface of ferric oxide. The results show that $\mathrm{O}-$ top and $\mathrm{O}$-hollow sites on the $\alpha$-ferric oxide acted as the active sites for As (III) adsorption, and the O-top activity is higher. The breakage of the As-O bond in the As (III) is the critical stage of As (III) adsorption, which is checked by comparing binding energy from various adsorption sites [14]. In the study of Fan et al. [15], DFT calculations were investigated for the mechanisms of As (III) adsorption on the $\mathrm{CaO}$ surface under oxygen atmosphere. These reactions could be categorized as three forms according to the energy barrier with the goal to represent the strength of the necessary reaction temperature. Also the number of superficial $\mathrm{CaO}$ occupied by As (III) is considered to describe the adsorption reaction equation [15]. Gao et al. [16] conducted a theoretical calculation on the effect on arsenic adsorption over carbonaceous surfaces of functional oxygen complexes and found that modified carbonaceous surfaces are highly adsorbent, consistent with experimental evidence. According to the previous study, the mechanism of inorganic arsenic and organic arsenic adsorption on the carbon surface of biochar prepared from hospital sludge is hardly any theoretical study. Therefore, the adsorption mechanism of amine functional complexes for arsenic adsorption over Sludge Biochar Carbon (SBC) needs to be clearly demonstrated. The inorganic arsenic and organic arsenic adsorption mechanisms on SBC and amine functional material (DETA-SBC) were systematically investigated using DFT calculation. The objectives of this work are (a) to prepare sludge biochar carbon and amine functional material, such as SBC and DETASBC for developing key reaction between arsenic and modified biochar; (b) to characterize sludge biochar carbon with nitrogen adsorption-desorption measurements, Fourier Transform Infrared Spectroscopy (FTIR) and Xray Photoelectron Spectroscopy (XPS) for verifying the mechanisms for adsorbing arsenic; (c) to obtain optimum operation conditions by assessing the effect of different diethylenetriamine amount on adsorbing inorganic arsenic and organic arsenic; (d) to investigate the intra-particle diffusion parameters of arsenic adsorption for developing arsenic adsorption mechanisms; and (e) to systematically calculate adsorption energy, bond distance and adsorbed structure through DFT.

\section{Materials and methods}

\section{Starting materials and chemicals}

Hospital sludge was obtained from Far Eastern Memorial Hospital water treatment plant $\left(1000 \mathrm{~m}^{3} \mathrm{~d}^{-1}\right)$ at New Taipei City in Taiwan. The sludge was carbonized in a microwave carbonization reactor. The microwave generator was used by Zhuzhou Wavelane Technology Co. (1000 W, Model Wemax A1). The sludge slurries were crushed and filtered (particle size of less than $0.1 \mathrm{~mm}$ ) before activation. Hydrochloric acid $(\mathrm{HCl})$, zinc chloride $\left(\mathrm{ZnCl}_{2}\right)$, sodium hydroxide $(\mathrm{NaOH})$ and Diethylenetriamine (DETA) were purchased from Ke-Hua Chemical Reagent Co. Inorganic arsenic (As (III)) and organic arsenic (Dimethylarsinic Acid, DMA) was obtained from high-purity standards. All chemical reagents were of analytical grade and directly used as received without further purification. Ultrapure water was obtained for the preparation of all solutions.

\section{Preparation of DETA-SBC}

DETA-SBC was prepared following the method as described below. Hospital sludge has some infectious bacteria or viruses, so hospital sludge needs to be treated with caution in the pretreatment stage and under special prescribed space conditions. In brief, in this study, infectious bacteria, viruses, and moisture of the sludge were removed in the decanter after pretreatment in a microwave oven at $1000 \mathrm{~W}$ for $30 \mathrm{~min}$ to obtain absolute preparation materials. To obtain the activated material, $50 \% \mathrm{ZnCl}_{2}$ and the as-synthesized carbonized sludge was added in $150 \mathrm{~mL}$ of deionized water, and stirred at $85 \pm$ $5{ }^{\circ} \mathrm{C}$ for $2 \mathrm{~h}$. The mixture was dehydrated in an oven at $110 \pm 5^{\circ} \mathrm{C}$ for $24 \mathrm{~h}$ and then pyrolyzed in a horizontal tubular furnace under nitrogen flow at different temperatures (include 300, 400, 500,600, 700 and $800 \pm 5^{\circ} \mathrm{C}$ ) for $2 \mathrm{~h}$. Then, $10 \mathrm{~g}$ of SBC was mixed with different amounts of DETA (including 0.7, 2.0, 3.3, 4.6 and 5.9\%) solution, and stirring for $2 \mathrm{~h}$. The mixture again was 
dehydrated in an oven at $110 \pm 5^{\circ} \mathrm{C}$ for $24 \mathrm{~h}$ after filtered and rinsed by deionized water.

\section{Materials characterization}

The pore volume, pore size distribution and specific surface area were determined by performing nitrogen adsorption-desorption measurements with an ASAP 2020 apparatus by using Barrett-Joyner-Halenda and Brunauer-Emmett-Teller calculation methods. The surface morphology of the biochar carbon was examined using a Scanning Electron Microscope (SEM, Nova-nano SEM 450). The FTIR (thermo Nicolet iS10 FTIR Spectrometer) of the biochar carbon was recorded to study the functional groups at room temperature. The composition of biochar carbon was further determined by XPS.

\section{Adsorption performance assessment}

Adsorption isotherm experiments were carried out in $100 \mathrm{~mL}$ adsorption system. The porous adsorbents were mixed with $50 \mathrm{~mL}$ of the appropriate arsenic solution at $25^{\circ} \mathrm{C}$ for $60 \mathrm{~min}$. The solution was filtered with using a membrane filter (pore size $0.45 \mu \mathrm{m}$ ). In addition, an inductively coupled plasma atomic emission spectroscopy with a detection limit for arsenic of $10 \mathrm{ppb}$ was used to evaluate the residual arsenic in the aqueous solutions. The test data were regularly calibrated using standard solution in order to obtain accurate data.

The exact amount of adsorbed As per adsorbent unit mass was determined by weight balance as follows Eq. (1):

$$
q_{e}=\frac{C_{o}-C_{e}}{W} \times V
$$

Where, the equilibrium adsorption capacity is $q_{e}$ (mg $\left.\mathrm{g}^{-1}\right), V(\mathrm{~mL})$ is the volume of As solution, $W(\mathrm{mg})$ is the amount of adsorbent used in the experiments, $C_{o}$ (mg $\mathrm{L}^{-1}$ ) is the initial concentration of As and the balance concentration measured after adsorption stands for $C_{e}$ $\left(\mathrm{mg} \mathrm{L}^{-1}\right)$.

\section{DFT model and computation detail}

The SBC surface is doped with DETA group to form other DETA-SBC structures. The two pollutants (As (III) and DMA) are adsorbed on the above DETA-SBC structures respectively after $10 \mathrm{~ns}$ molecular dynamics simulation. Finally, adsorption systems were constructed in the same cubic simulation lattice built with their dimensions of $\mathrm{x}=10 \AA \mathrm{y}=10 \AA$, and $\mathrm{z}=14 \AA$.

In Materials Studio 2018, all the DFT calculations in this analysis were carried out using the $\mathrm{DMol}^{3}$ software kit [17]. The terms of exchange and correlation were determined in the form proposed by Perdew, Burke, and
Ernzerhof using the Generalized Gradient Approximation [18]. The core DFT semi-core pseudo potential method was utilized to calculate the core treatment of DETA, for other elements, the all-electron method was applied [19]. Solvation effects were incorporated by conductor-like polarizable continuum model for all the systems with water as solvent. The adsorption energy $\left(E_{\text {ads }}\right)$ of pollute molecules on DETA-SBC surface was calculated by the following Eq. (2) [20]:

$$
\mathrm{E}_{\mathrm{ads}}=\mathrm{E}_{\mathrm{DETA}-\mathrm{SBC}-\text { pollute }}-\left(\mathrm{E}_{\mathrm{DETA}-\mathrm{SBC}}+\mathrm{E}_{\text {pollute }}\right)
$$

Where, $E_{D E T A-S B C}$ and $E_{\text {pollute }}$ respectively represent the energies of the DETA-SBC surface and the single pollute molecule, and the $E_{\text {DETA-SBC-pollute }}$ is the total energy of pollute-DETA-SBC complex.

According to Eq. (2), a negative value of $E_{\text {ads }}$ indicates that the process is an exothermic reaction and high negative value corresponds to a stronger interaction, which indicates more heat release and a more stable product.

\section{Results and discussion}

\section{Characterization of materials}

This study investigated the effect of carbonization at different temperature on biochar carbon. The morphology and pore structure of SBC are shown in Fig. 1. The carbonized temperature significantly affected the formation of pore structure. The results showed that $\mathrm{SBC}$ has a uniform pore at $500^{\circ} \mathrm{C}$, as shown in Fig. 1c, but the $\mathrm{SBC}$ did not have any pores at 300 and $400^{\circ} \mathrm{C}$, as shown in Fig. 1a and Fig. 1b. The pores of material are decreasing, when the carbonization temperature increases from 500 to $800^{\circ} \mathrm{C}$, it is possible that carbonization at a relatively high temperature can thin the material's pore wall, making the pores more vulnerable to destruction, as shown in Fig. 1d and Fig. 1f. The best activation ratio of carbonized sludge over $\mathrm{ZnCl}_{2}$ was found to be 1:1, and the results are listed in Table 1 . The surface area, pore volume, and pore size of the un-activated SBC composites were estimated to be $96 \mathrm{~m}^{2} \mathrm{~g}^{-1}, 0.73 \mathrm{~cm}^{3} \mathrm{~g}^{-1}$ and 5.06 $\mathrm{nm}$, respectively. In contrast, the surface area, pore volume, and pore size of the $50 \% \mathrm{ZnCl}_{2}-\mathrm{SBC}_{2}$ composites were estimated to be $525 \mathrm{~m}^{2} \mathrm{~g}^{-1}, 0.35 \mathrm{~cm}^{3} \mathrm{~g}^{-1}$ and 8.71 $\mathrm{nm}$, respectively. The isotherms belonged to Type IV and suggested that $\mathrm{N}_{2}$ was condensed in the pores at high relative pressure [21]. The changes in the functional groups of SBC before and after activation were analyzed by FTIR spectroscopy: it is seen that chemicals are well mixed with raw material as shown in Fig. 2. The $-\mathrm{OH}$ and $\mathrm{N}-\mathrm{H}$ stretching vibration band are characteristic peaks of the amine group at about $3410 \mathrm{~cm}^{-1}$ [22] and C-O vibrations at $1760 \mathrm{~cm}^{-1}$ disappeared for all SBC [23]. The appearance of peaks at 2930 and $2849 \mathrm{~cm}^{-1}$ in 

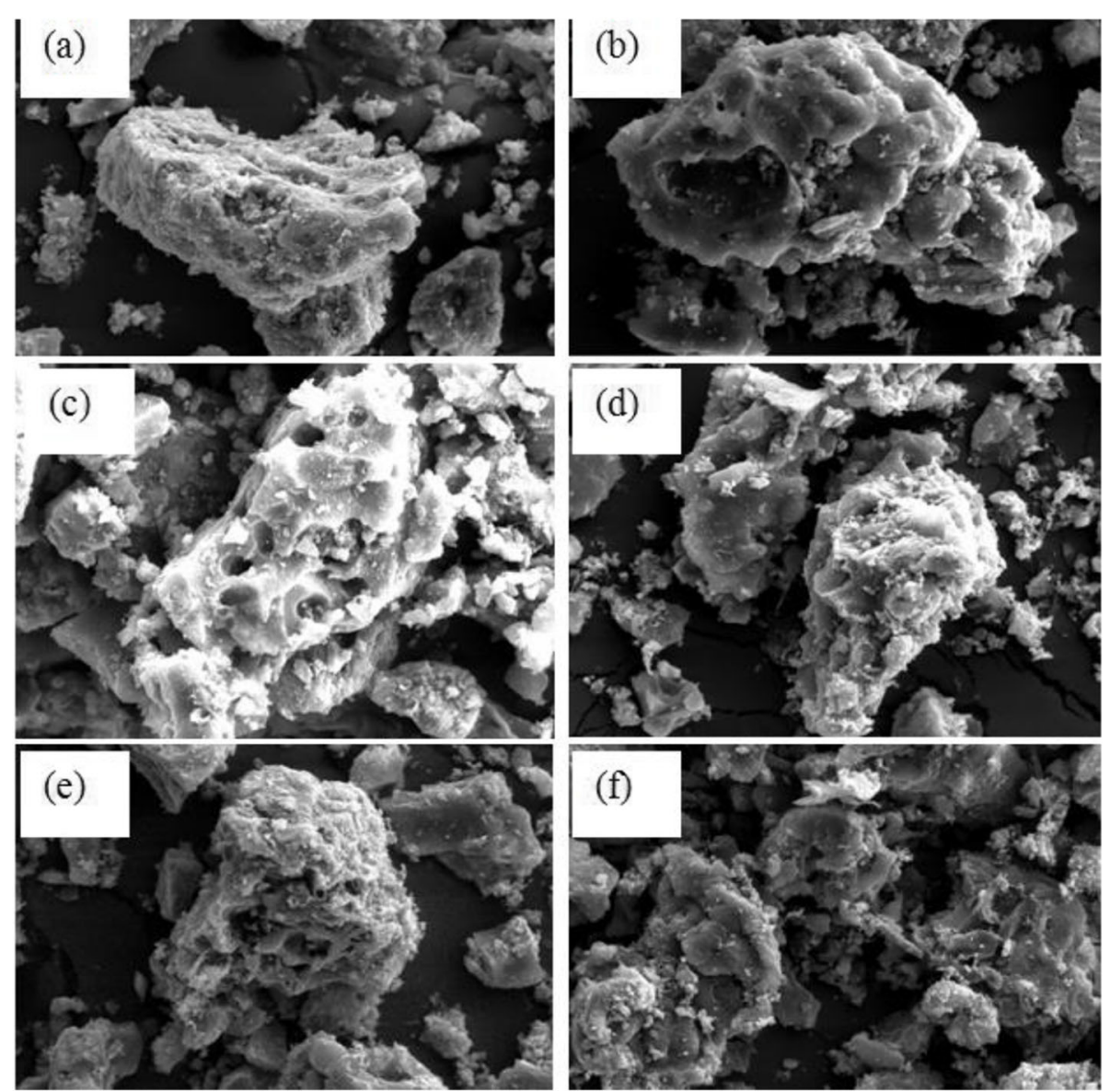

Fig. $1 \mathrm{SEM}$ micrograph of SBC at different temperatures: (a) $300^{\circ} \mathrm{C}$, (b) $400{ }^{\circ} \mathrm{C}$, (c) $500^{\circ} \mathrm{C}$ (d) $600{ }^{\circ} \mathrm{C}$, (e) $700{ }^{\circ} \mathrm{C}$ and (f) $800^{\circ} \mathrm{C}$

the spectrum was attributed to $\mathrm{C}-\mathrm{H}$ stretching vibration in $-\mathrm{CH}$ and $-\mathrm{CH}_{2}$ [22]. The band at $1620 \mathrm{~cm}^{-1}$ can be ascribed to $\mathrm{C}-\mathrm{C}$ aromatic ring stretching vibration [23]. The band at $1473-1435 \mathrm{~cm}^{-1}$ is ascribed to $\mathrm{C}-\mathrm{H}$ bending vibrations in $\mathrm{CH}_{2}$ groups [22]. The existence of bands about $1040-1100 \mathrm{~cm}^{-1}$ which was assigned to $\mathrm{SiO}_{2}$ represented the nature of the feedstock, and these bands were observed in all biochar carbon [24]. There is a weak vibration band between 765 and $530 \mathrm{~cm}^{-1}$, which is judged as an aromatic structure. Due to the large amount of organic matter in the sludge, the chemical structure is composed of a large number of different atoms. Therefore, there are more functional groups. The XPS spectrum of the SBC

Table 1 The surface area and pore volume of materials

\begin{tabular}{llll}
\hline Material & $\mathbf{S}_{\text {BET }}\left(\mathbf{m}^{\mathbf{2}} \mathbf{g}^{-\mathbf{1}}\right)$ & $\mathbf{V}_{\text {meso }}\left(\mathbf{c m}^{\mathbf{3}} \mathbf{g}^{-\mathbf{1}}\right)$ & $\mathbf{d}_{\mathbf{p}}(\mathbf{n m})$ \\
\hline SBC & 96 & 0.73 & 5.06 \\
$33 \% Z n{ }_{2}-S B C$ & 378 & 0.27 & 7.25 \\
$50 \% \mathrm{ZnCl}_{2}-\mathrm{SBC}$ & 525 & 0.35 & 8.71 \\
$60 \% \mathrm{ZnCl}_{2}-\mathrm{SBC}$ & 516 & 0.34 & 7.66 \\
$67 \% \mathrm{ZnCl}_{2}-\mathrm{SBC}$ & 436 & 0.29 & 6.87 \\
\hline
\end{tabular}

hybrid sample is shown in Fig. 3a, illustrating the characteristic peak of $\mathrm{C}, \mathrm{N}$ and $\mathrm{O}$. The results show that doublebonding carbons for SBC are assigned the highest peak at $285 \mathrm{eV}$. The peak of approximately $285 \mathrm{eV}$ binding energy for SBC is a result of single carbon bonding $[25,26]$. In the DETA-SBC high-resolution N1s region, as shown in Fig. 3b, due to neutral amine nitrogen (-NH-) from the DETA chains, there is an extreme peak at $399 \mathrm{eV}$. When the DETA is doped on SBC, the main component of the N1s peak shifts to $400 \mathrm{eV}$, referring to the amine nitrogen (-NH-) [27].

\section{Effect of DETA content}

In this section, it discusses the impact of the amino group density grafted on the SBC loading number. The density of amino groups will vary with the different DETA material added during the synthesis procedure. Different DETA content, including $0.7,2.0,3.3,4.6$ and $5.9 \%$ was evaluated with $3.0 \mathrm{~g} \mathrm{~L}^{-1}$ of DETA-SBC at $0.5 \mathrm{mg} \mathrm{L}^{-1}$ As (III) and DMA for 30 min contact time. Figure 4 shows the removal efficiency of As (III) and DMA significantly increases from 41 to $86 \%$ and 52 to $97 \%$, respectively, with increasing DETA content from 0.7 to $5.9 \%$. However, the removal 


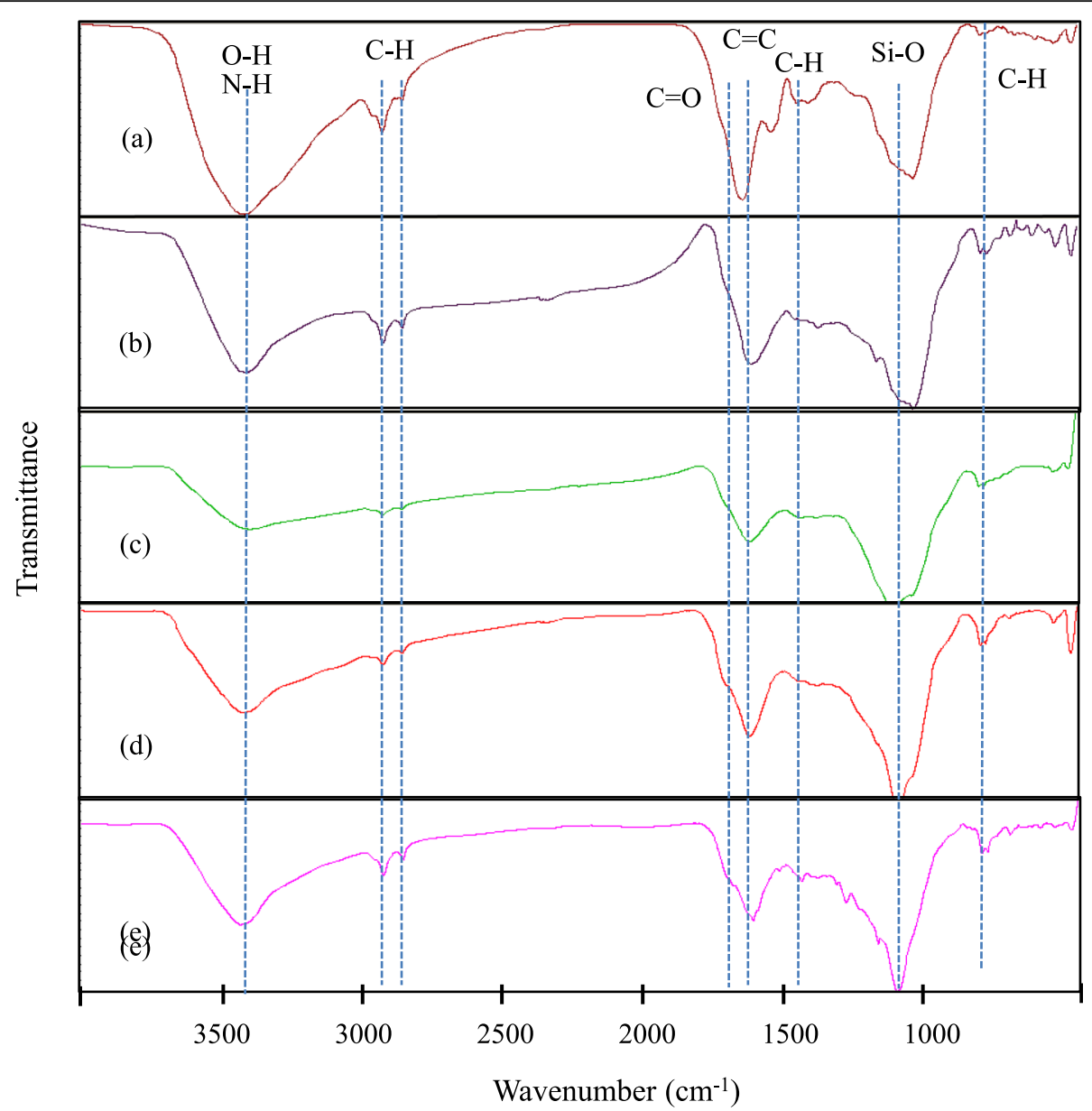

Fig. 2 FTIR spectrums of (a) SBC, (b) $33 \% \mathrm{ZnCl}_{2}-\mathrm{SBC}$, (c) $50 \% \mathrm{ZnCl}_{2}-\mathrm{SBC}$, (d) $60 \% \mathrm{ZnCl}_{2}-\mathrm{SBC}$ and (e) $67 \% \mathrm{ZnCl}_{2}-\mathrm{SBC}$

efficiency is not changed with increasing the DETA content from 4.6 to $5.9 \%$. In this study, it shows that the amino groups impregnated on SBC can enhance the adsorption capacity for As (III) and DMA. The higher DETA content does not increase the removal efficiency, but can increase the cost of the material preparation. The adsorption capacity of As (III) and DMA was calculated as 1.6 and $2.0 \mathrm{mg} \mathrm{g}^{-1}$, respectively, with $4.6 \%$ DETA-SBC.

\section{Effects of $\mathrm{pH}$}

The $\mathrm{pH}$ level is an important controlling parameter during adsorption, because $\mathrm{pH}$ affects the surface properties of the adsorbent as well as the speciation of substrates. The effect of pH on the adsorption of As (III) and DMA were studied with $0.5 \mathrm{mg} \mathrm{L}^{-1}$ arsenic solution using 3.0 $\mathrm{g} \mathrm{L}^{-1}$ of DETA-SBC material for $30 \mathrm{~min}$ contact time. The removal efficiencies of As (III) and DMA at $\mathrm{pH}$ values in the range of 3-11 are depicted in Fig. 5. The highest removal efficiency is $93 \%$ at $\mathrm{pH} 3.0$ with the As (III) adsorption capacity $1.5 \mathrm{mg} \mathrm{g}^{-1}$. The lower $\mathrm{pH}$ value increased the number of positively charged sites and reduced the number of negatively charged sites. This process created electrostatic between the positively charged surface of the absorbent and the anionic As (III). In other pathway is the complex interaction between the amino functional group on the surface of DETA-SBC and As (III), causing arsenic to be adsorbed on the DETA-SBC surface. On the other hand, the removal efficiencies of DMA significantly increase from 75 to $98 \%$ with increasing of $\mathrm{pH}$ value from 3.0 to 9.5 . In contrast, the removal efficiency is decreased from 98 to $54 \%$ with increasing $\mathrm{pH}$ value from 9.5 to 11.0 . The highest removal efficiency is $98 \%$ at $\mathrm{pH} 9.5$ with DMA adsorption capacity is $2.2 \mathrm{mg} \mathrm{g}^{-1}$ and drops to 0.51 $\mathrm{mg} \mathrm{g}^{-1}$ at $\mathrm{pH} 11$. The $\mathrm{pKa}$ values of DMA are 1.9, 4.1 and 9.2, respectively [28]. The ionization of DMA should be enhanced with increasing the solution $\mathrm{pH}$. Electrostatic interactions between the anionic form of DMA and positively charged DETA-SBC can therefore easily occur below $\mathrm{pH} 9.5$. While $\mathrm{pH}>9.5$, the adsorption capacity should decrease due to the 

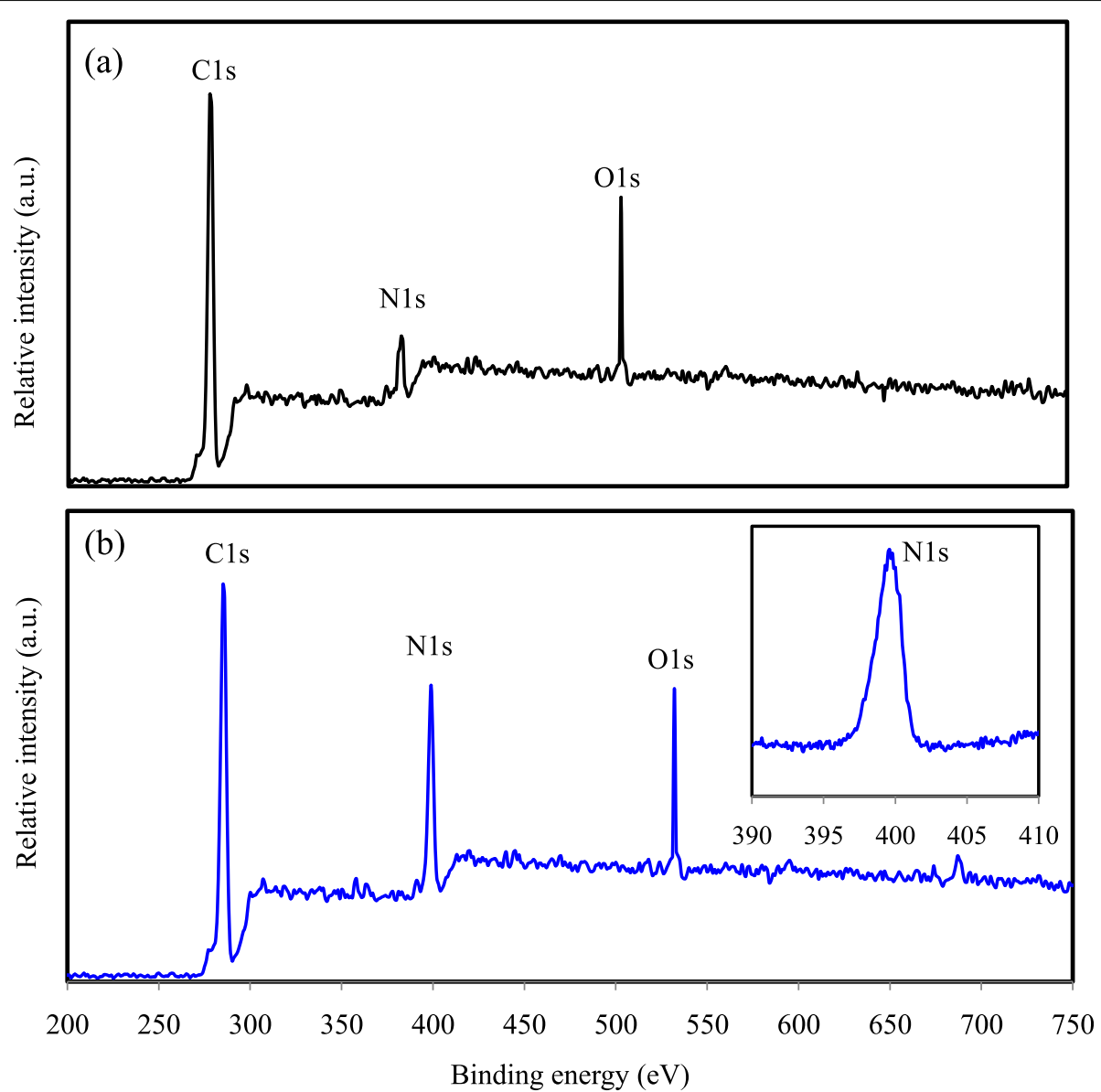

Fig. 3 XPS spectra of (a) SBC and (b) DETA-SBC

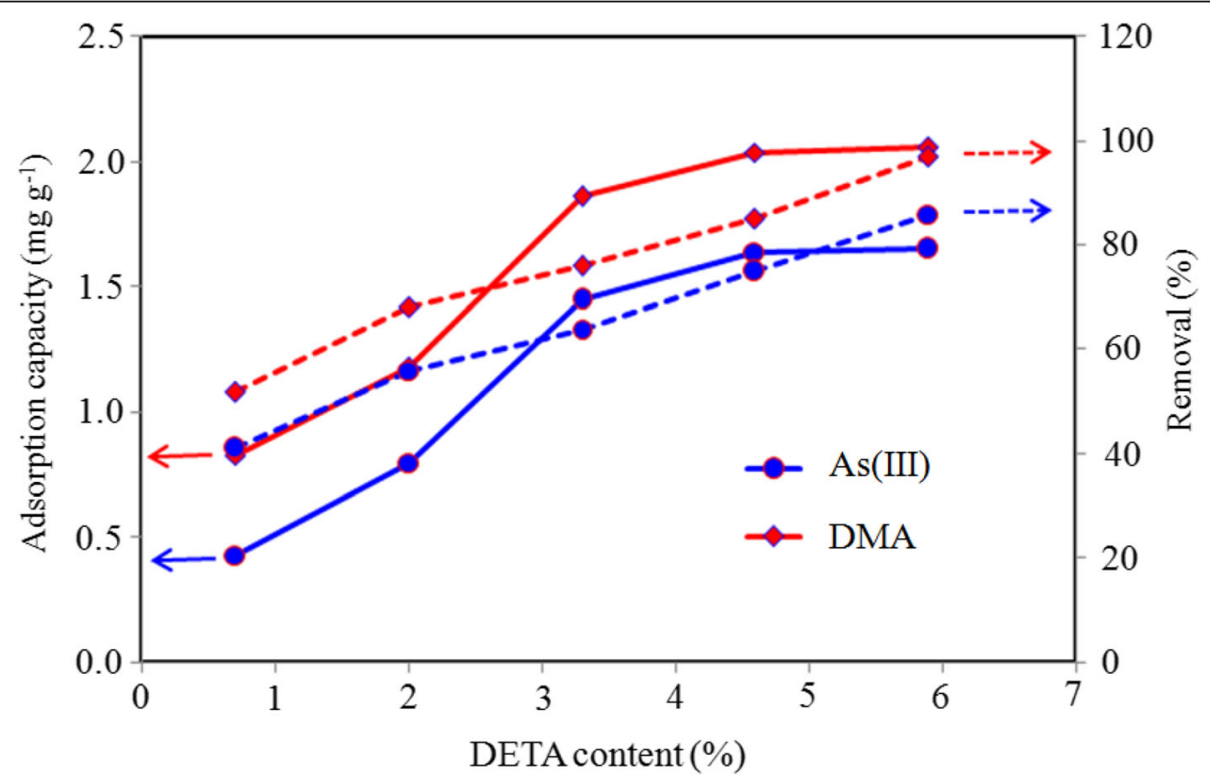

Fig. 4 Effect of grafted amino density on the adsorption performance 


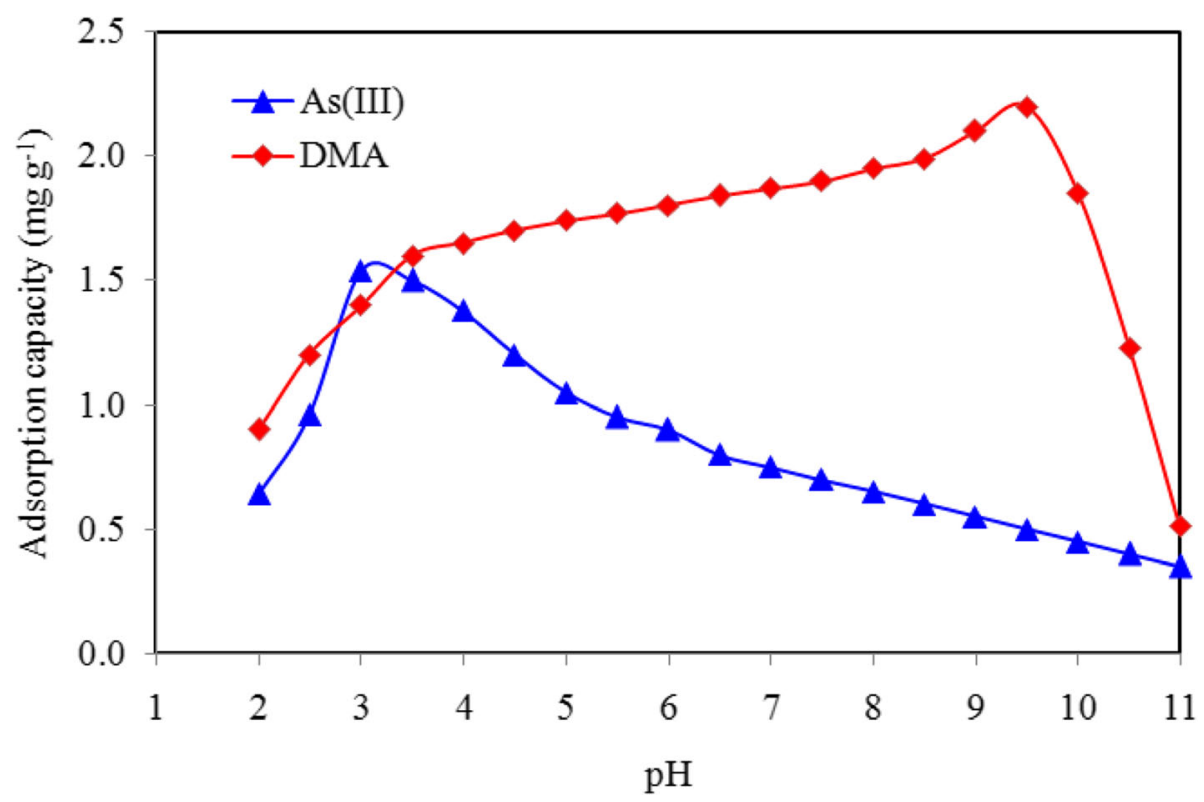

Fig. 5 Effect of different $\mathrm{pH}$ on the arsenic adsorption performance

repulsion between negatively charged DETA-SBC and DMA or affected by the competition of $-\mathrm{OH}$. The other researchers reported the similar results such as $\mathrm{Fu}$ et al. [29].

\section{Effects of recycle times}

The adsorption capacity of As (III) and DMA on 4.6\%DETA-SBC is not substantially changed after six recycles of the adsorption-desorption processes, as shown in Fig. 6. Most of the adsorbed arsenic species can be desorbed from biochar by the alkaline at $\mathrm{pH}$ 11.5 , which is in good accordance with the previous results on the effect of $\mathrm{pH}$ on arsenic species adsorption. However, after six recycles of the adsorptiondesorption processes, the adsorption capacity of the arsenic on $4.6 \%$ DETA-SBC exhibited an obvious decline. It is possible that the structure of the

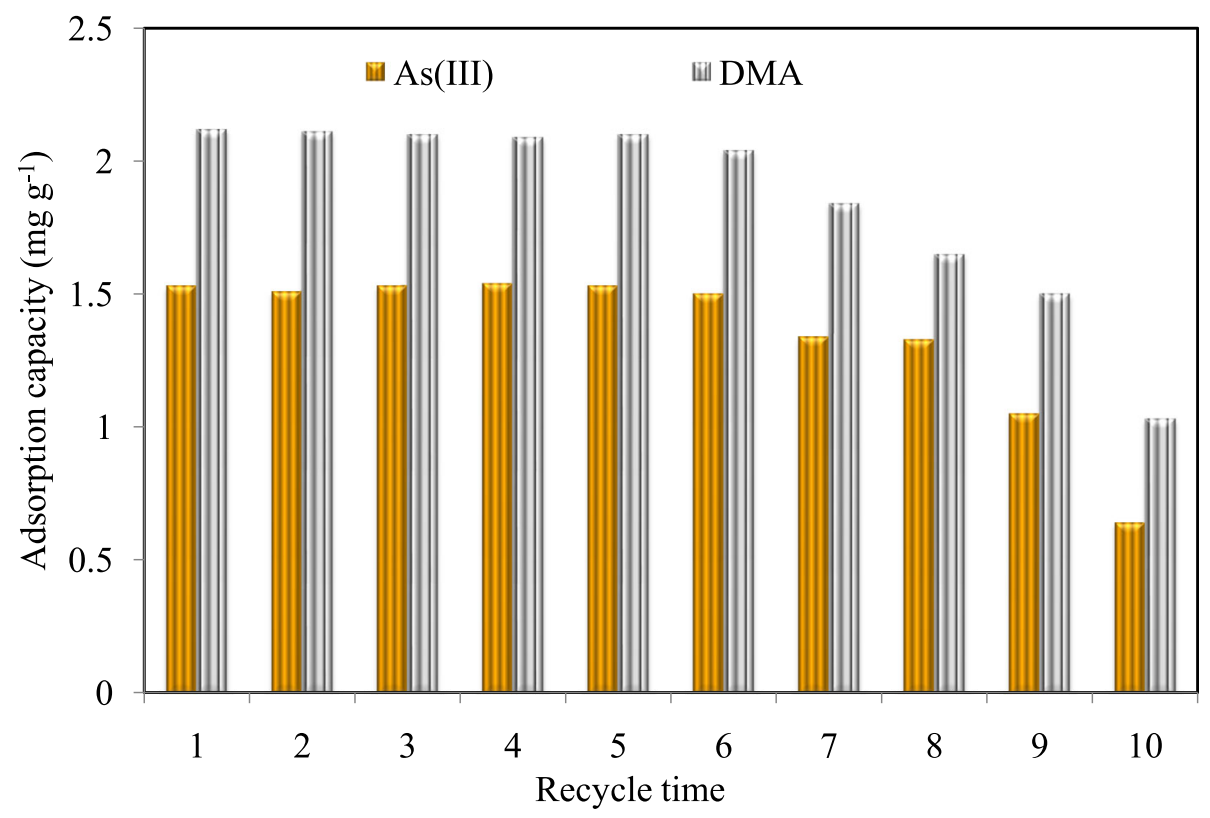

Fig. 6 The uptake of arsenic by biochar in consecutive adsorption-desorption cycles 


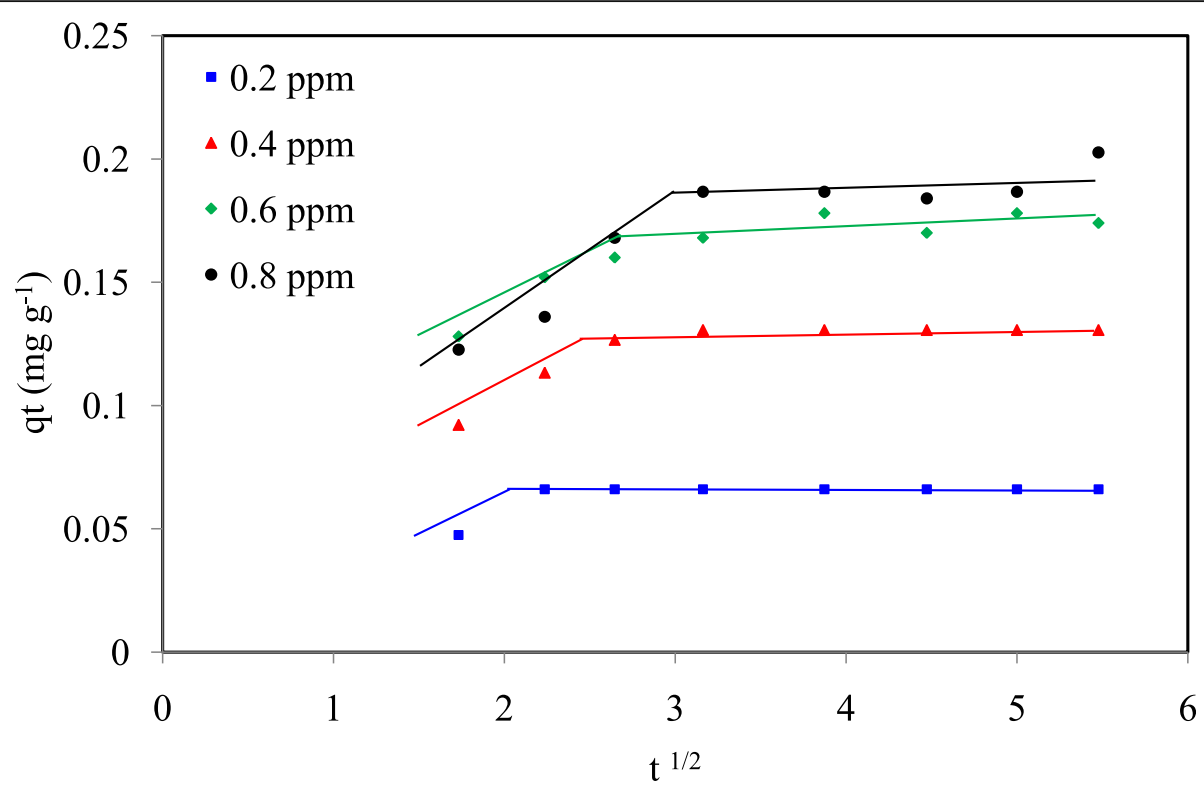

Fig. 7 Plot of the intra-particle diffusion equation for the adsorption of arsenic

4.6\%DETA-SBC starts to deteriorate and the amino groups are detached.

\section{Intra-particle diffusion model}

The rate limiting step was calculated with the intraparticle diffusion model to better understand the adsorption mechanism. The results fitted and the parameters derived from this model as shown in Fig. 7. Their correlation coefficient $\left(R^{2}\right)$ obtained fell within the range of 0.618-0.986. The plots were multi-linear and show their various processes of adsorption. The first line shows that a sharper portion is due to the spread of arsenic through the solution to the external adsorbent surface, as show in the intra-particle diffusion model. The second line defines the gradual stage of adsorption, in which intraparticle diffusion limits the rate. This result is similar to the results of Xiong et al. [30].

The physi-adsorption configurations of as (III) and DMA on SBC

Finite benzene clusters from single layer activated carbon structure were used in this analysis to simulate surface models of SBC, as shown in Fig. 8a. First, the adsorption of inorganic and organic arsenic to $\mathrm{SBC}$ is

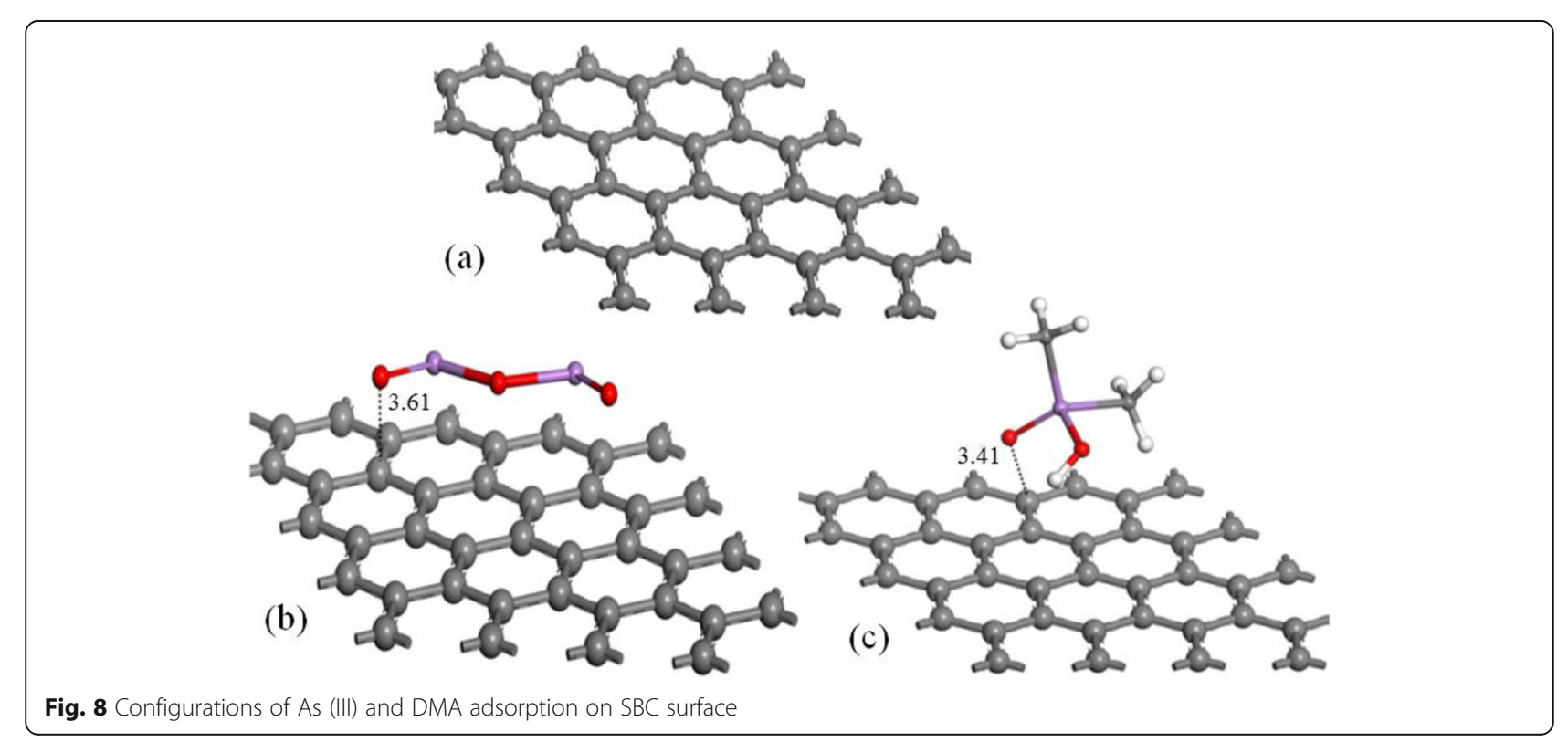


Table $2 E_{a d s}$ value of As (III) and DMA adsorbed onto each material

\begin{tabular}{llll}
\hline Material & Bond & Bond distance $(\AA)$ & $\boldsymbol{E}_{\text {ads }}\left(\mathbf{k J ~} \mathbf{~ o l}^{-\mathbf{1}}\right)$ \\
\hline SBC & C-As (b) & 3.61 & -21.1 \\
& C-As (c) & 3.41 & -27.5 \\
DETA-SBC & C- N (a) & 1.61 & -291.7 \\
& N-As (b) & 3.26 & -32.4 \\
& N-As (c) & 2.92 & -38.8 \\
\hline
\end{tabular}

predicted to be unstable, as SBC is inefficient for the removal of arsenic. As observed in Fig. 8b, Fig. 8c and Table 2, the As (III) and DMA are adsorbed onto SBC with $E_{a d s}$ value of -21.1 and $-27.5 \mathrm{~kJ} \mathrm{~mol}^{-1}$, respectively, in different conformations, indicating a physical adsorption between arsenic and SBC surface since $E_{\text {ads }}$ value is smaller than $-50 \mathrm{~kJ} \mathrm{~mol}^{-1}$ [16]. The bond distance of $\mathrm{C}-\mathrm{O}$ bond is $3.61 \AA$ (Fig. 8b) and the bond distance of $\mathrm{C}-\mathrm{O}$ bond is $3.41 \AA$ (Fig. $8 \mathrm{c})$. It illustrates that DMA adsorbed onto $\mathrm{SBC}$ is stronger than As (III) adsorbed onto SBC verified by its larger $E_{\text {ads }}$ value.
The physi-adsorption configurations of as (III) and DMA on DETA-SBC

The results for the adsorption of As (III) and DMA on the DETA doped onto SBC surface are summarized in Table 2 and Fig. 9. The DETA doped onto SBC surface with $E_{\text {ads }}$ values of up to $-291.7 \mathrm{~kJ} \mathrm{~mol}^{-1}$, the adsorption energies of DETA-SBC are all large enough to anchor DETA atom firmly. The bond distance of $\mathrm{C}-\mathrm{N}$ bond is $1.61 \AA$ (Fig. 9a). Interestingly, when the DETA doped onto SBC is used for adsorption of both anionic As (III) and DMA an improvement in the adsorption is achieved. Results show the As (III) and DMA are adsorbed onto DETA-SBC surface with $E_{\text {ads }}$ values of up to -38.8 and $-32.4 \mathrm{~kJ} \mathrm{~mol}^{-1}$, respectively, in different conformations, indicating a physical adsorption between arsenic and DETA-SBC surface. The bond distance of N-As bond is $2.26 \AA$ (Fig. 9b) and the bond distance of N-As bond is $3.92 \AA$ (Fig. 9c). It illustrates that DMA adsorbed onto DETA-SBC is also stronger than As (III) adsorbed onto DETA-SBC verified by its larger $E_{\text {ads }}$ value.

The possible chemi-adsorption configurations of as (III) and DMA on DETA-SBC

The results for the adsorption of inorganic and organic arsenic on the DETA-SBC surface displays all the

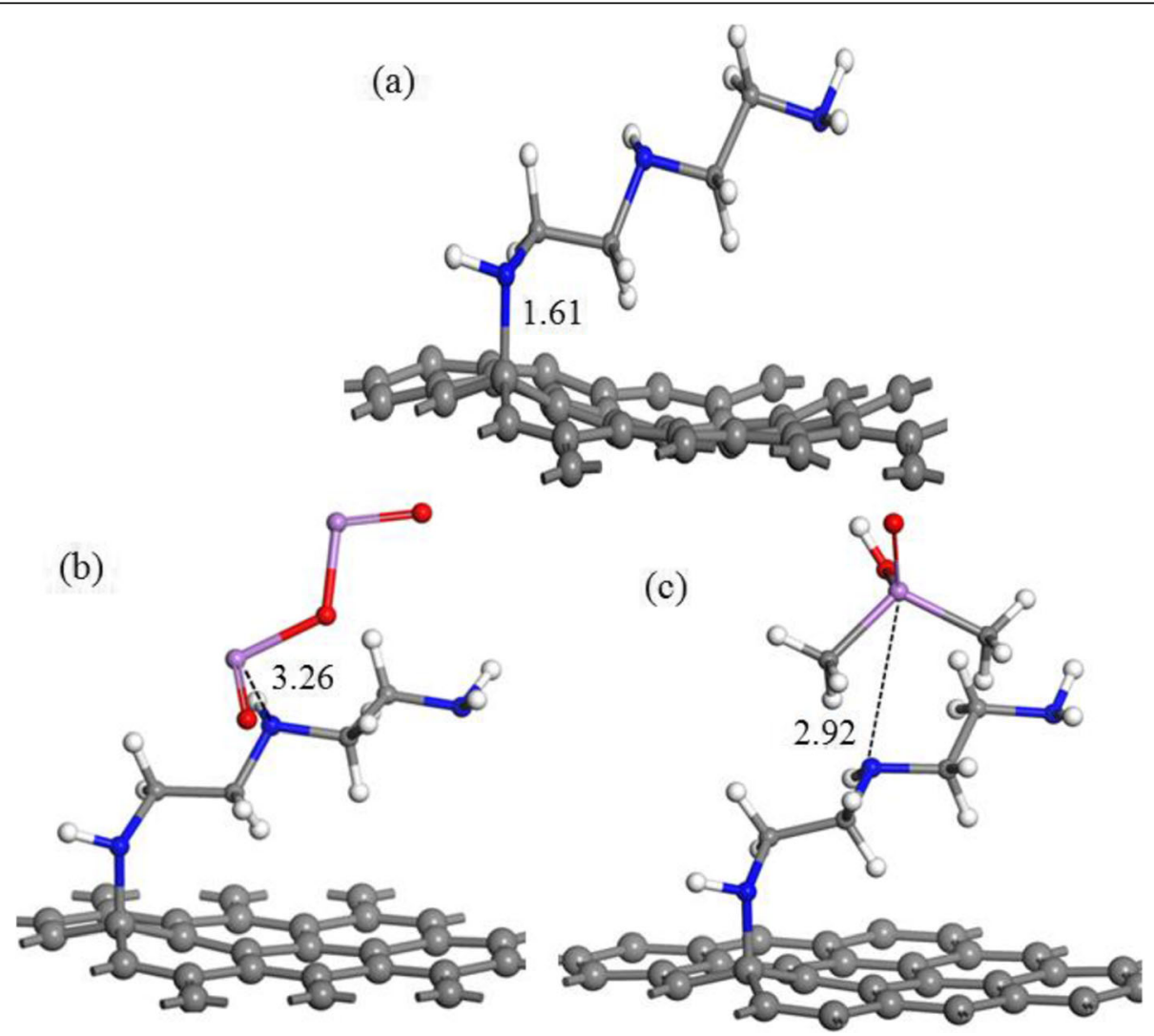

Fig. 9 Configurations of (a) As (III) and (b) DMA adsorption on DETA-SBC surface 

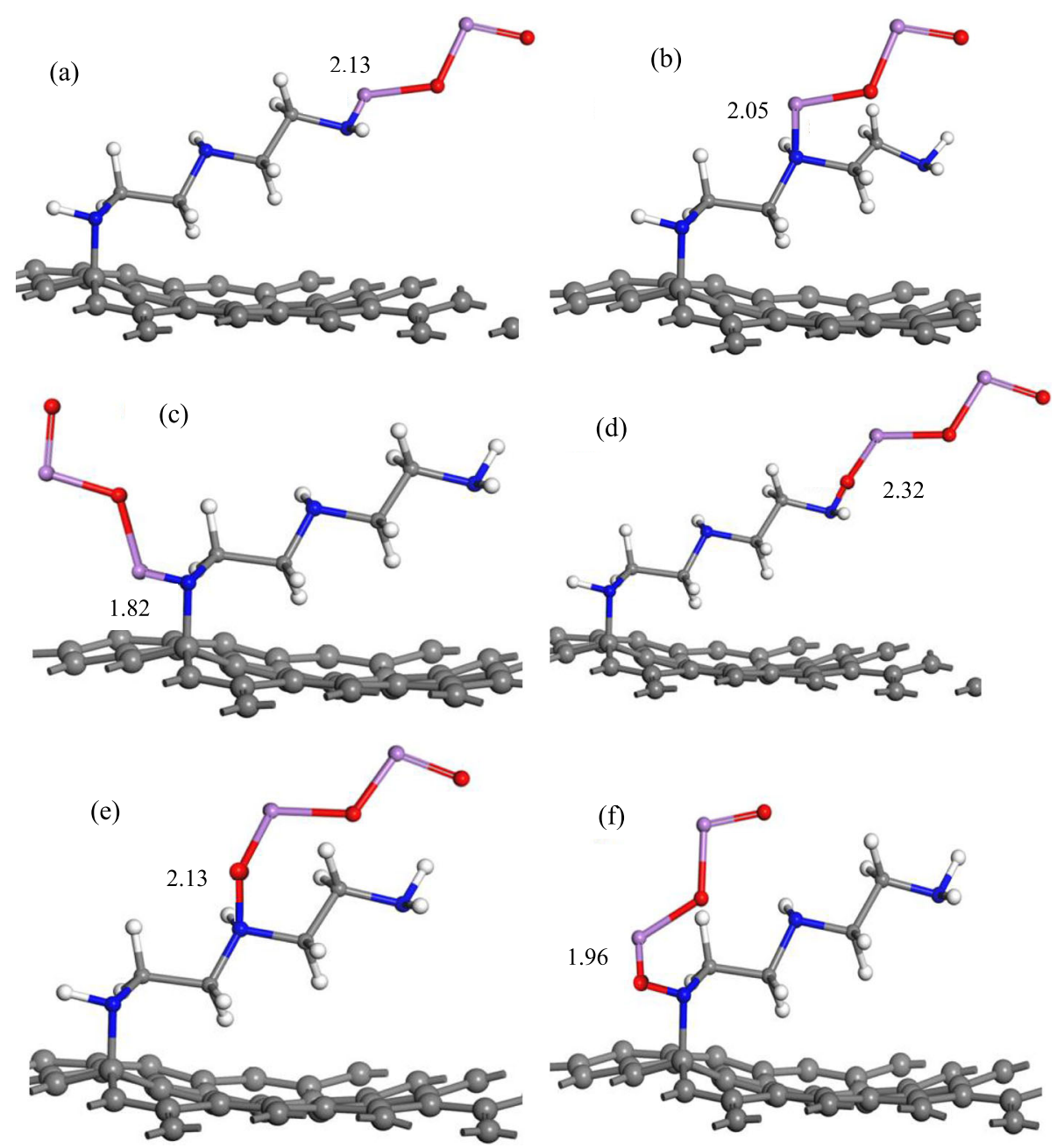

Fig. 10 The possible adsorption configurations of As (III) on DETA-SBC

Table 3 Adsorption energies of As (III) and DMA adsorbed onto DETA-SBC surface

\begin{tabular}{|c|c|c|c|}
\hline Pollutant & Bond & Bond distances $(\AA)$ & $E_{\mathrm{ads}}\left(\mathrm{kJ} \mathrm{mol}^{-1}\right)$ \\
\hline \multirow[t]{6}{*}{ As (III) } & N-As (a) & 2.05 & -79.5 \\
\hline & N-As (b) & 2.13 & -52.4 \\
\hline & $\mathrm{N}-\mathrm{As}(\mathrm{c})$ & 1.82 & -92.9 \\
\hline & $\mathrm{N}-\mathrm{O}(\mathrm{d})$ & 2.32 & -61.5 \\
\hline & $\mathrm{N}-\mathrm{O}(\mathrm{e})$ & 2.13 & -83.6 \\
\hline & $\mathrm{N}-\mathrm{O}(\mathrm{f})$ & 1.96 & -90.7 \\
\hline \multirow[t]{6}{*}{ DMA } & N-As (a) & 2.16 & -74.6 \\
\hline & $\mathrm{N}-\mathrm{As}(\mathrm{b})$ & 2.12 & -76.2 \\
\hline & $\mathrm{N}-\mathrm{As}(\mathrm{c})$ & 1.91 & -94.3 \\
\hline & $\mathrm{N}-\mathrm{O}(\mathrm{d})$ & 2.23 & -53.4 \\
\hline & $\mathrm{N}-\mathrm{O}(\mathrm{e})$ & 2.14 & -75.5 \\
\hline & $\mathrm{N}-\mathrm{O}(\mathrm{f})$ & 1.92 & -98.5 \\
\hline
\end{tabular}

obtained conformations in Fig. 10 and Table 3 shows the bond type, bond distances and adsorption energies. Six possible adsorption configurations were considered in Fig. 10 to obtain the As (III)'s most stable adsorption configuration. The mostly mono-dentate conformations have been found. The bond distances of N-As and N-O are in the range between $2.05-1.82 \AA$ and $2.32-1.96 \AA$, respectively, which are shorter for the trivalent compounds in compliance with the increased adsorption energies, between -52.4 and $-92.9 \mathrm{~kJ} \mathrm{~mol}^{-1}$. The conformation in Fig. 10c shows higher adsorption energy than that of the others. Additionally, six ground state adsorption conformations for DMA were obtained (Fig. 11). With regards to the adsorption of DMA on the surface of DETA-SBC, DMA gained electron, while DETA and biochar carbon lost electron. Accordingly, the adsorption of DMA on the surface of DETA-SBC belongs to stable chemisorption. Configuration Fig. 11d tends to have a 

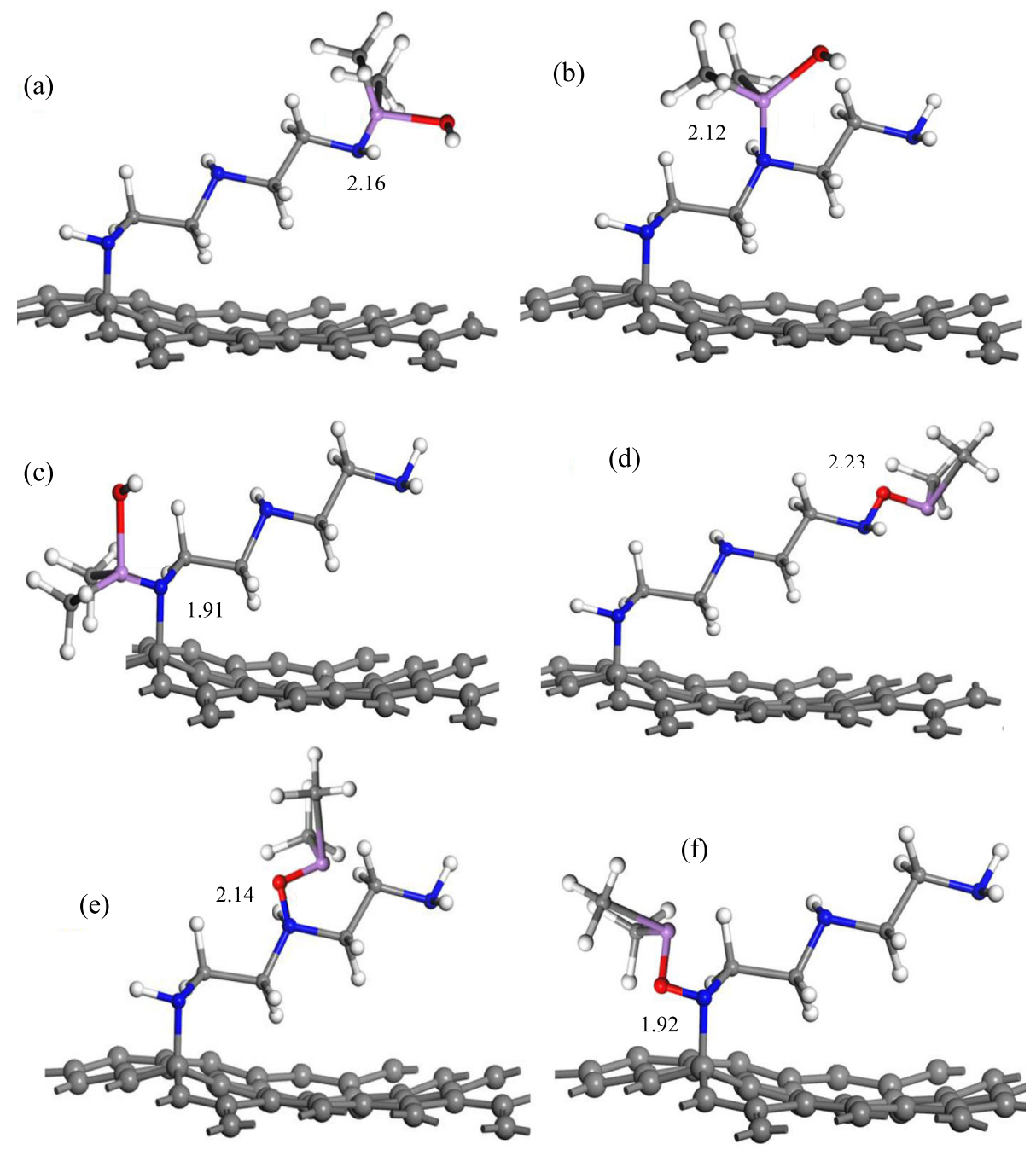

Fig. 11 The possible adsorption configurations of DMA on DETA-SBC

weak chemical reaction within, which corresponds with $-53.4 \mathrm{~kJ} \mathrm{~mol}^{-1}$ of adsorption energy. Otherwise, adsorption energy of configuration Fig. 11c is $-98.5 \mathrm{~kJ} \mathrm{~mol}^{-1}$; this suggests a strong chemical adsorption between the surface DMA and DETA-SBC. In recent years, DFT simulates the adsorption mechanism of arsenic adsorbed on the surface of the different materials as shown in Table 4.

\section{Mechanism discussion of arsenic adsorption by DETA-SBC material}

The mechanism for the adsorption of arsenic by biochar has been proposed with the results obtained from the experimental data, as presented in Fig. 12. The reaction mechanism is divided into three pathways. The first pathway is the attachment of arsenic ions into the pore of DETA-SBC material via physical adsorption, which may be attributed to van der Waals forces [31]. In the
Table 4 DFT simulates the adsorption mechanism of arsenic adsorbed on the surface of the different materials

\begin{tabular}{llll}
\hline No. & Material & Pollutant & Ref. \\
\hline 1 & CaO & As (III) & {$[15]$} \\
2 & Carbonaceous & As (III) & {$[16]$} \\
3 & Fe-doped graphene & As (III) & {$[35]$} \\
4 & $\mathrm{MnO}$ & As (III) and As(V) & {$[36]$} \\
5 & $\mathrm{ZnO}$ & As (III) and As(V) & {$[37]$} \\
6 & Nitrogen-doped carbon & As (III) and As(V) & {$[38]$} \\
7 & $\mathrm{TiO}_{2}$ nanocrystals & As (III) and As(V) & {$[39]$} \\
8 & Fe (III) and Fe (III) nanophases & As (III) and As(V) & {$[40]$} \\
9 & a-Al $\mathrm{O}_{3}$ & As(V) & {$[41]$} \\
10 & DETA-SBC & As (III) & This study \\
11 & DETA-SBC & DMA & This study \\
\hline
\end{tabular}




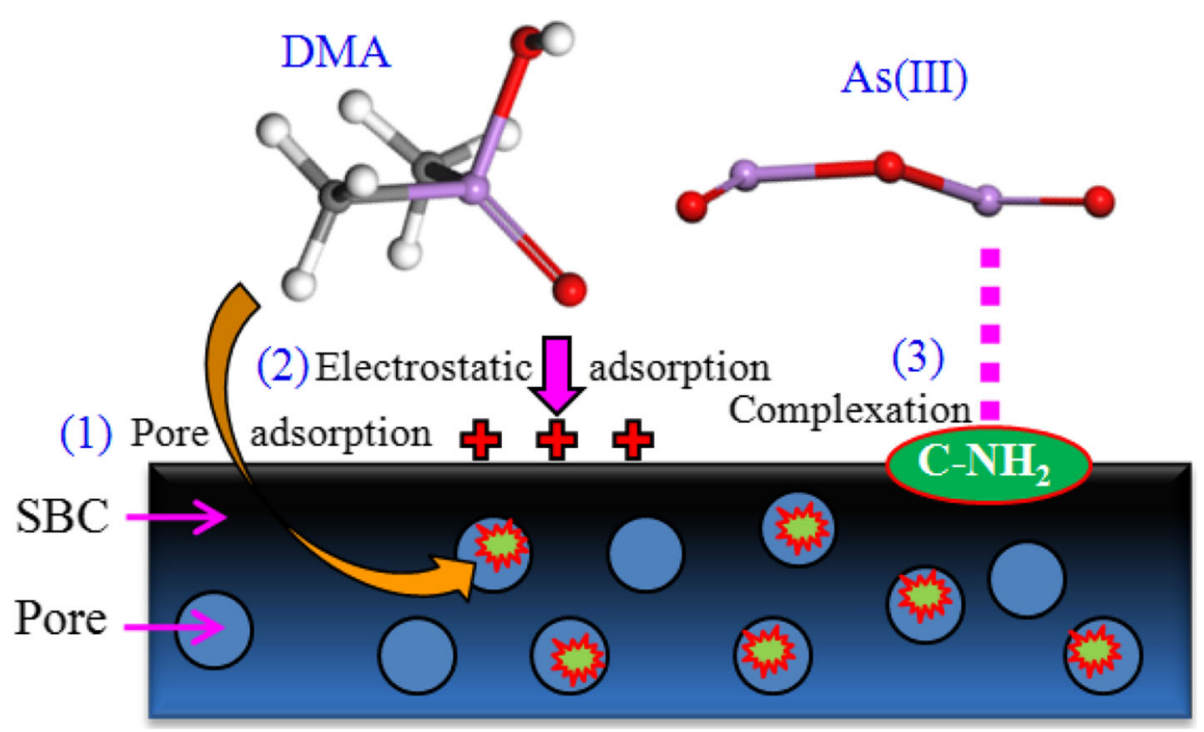

Fig. 12 The schematic diagram of mechanism for arsenate adsorption on DETA-SBC
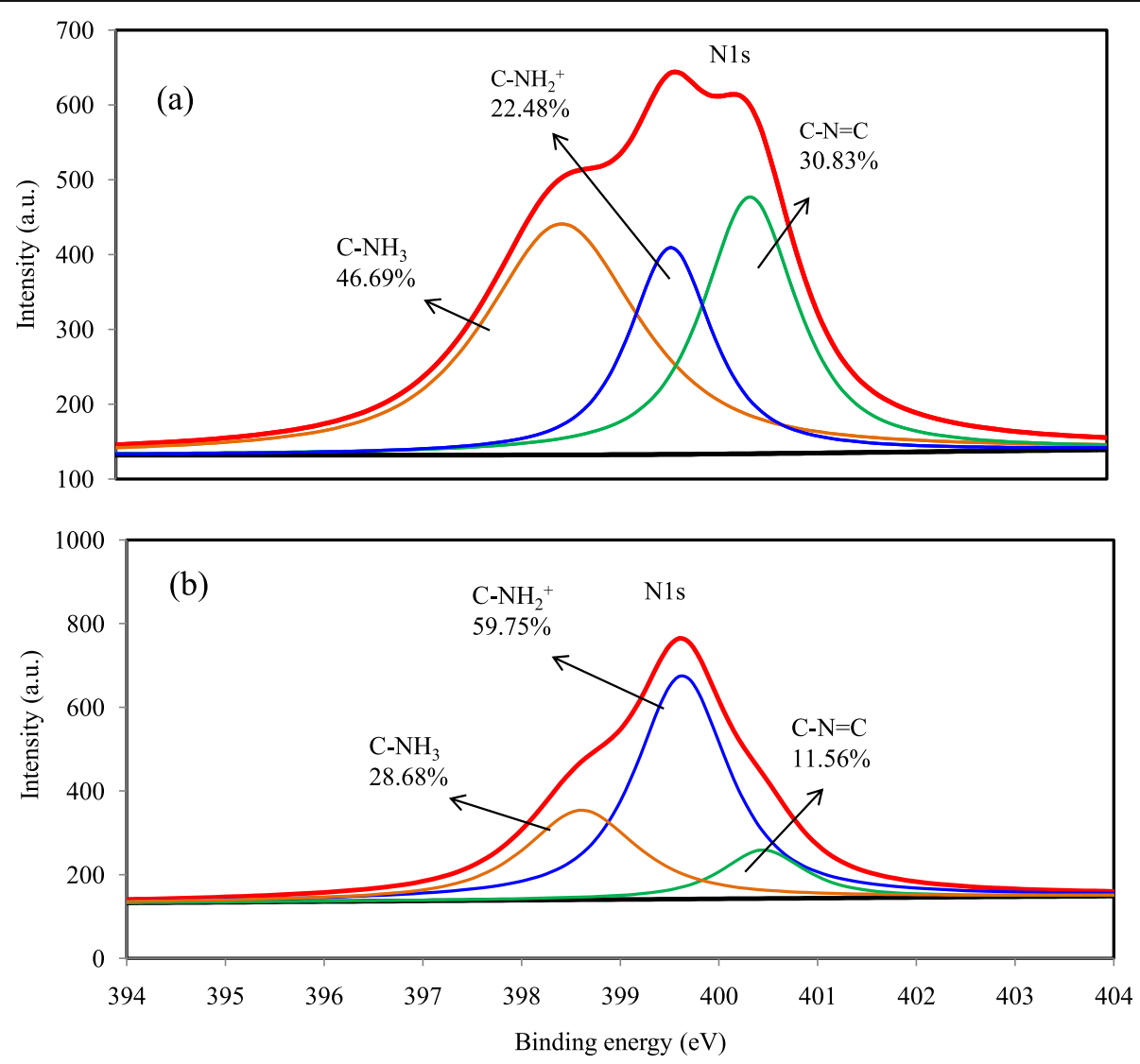

Fig. 13 XPS of the N1s state of DETA-SBC: (a) before and (b) after the As adsorption 
second pathway, the surface charge of amino-functional biochar is positive because of the protonation effect of amine groups when the $\mathrm{pH}$ solution is lower than $\mathrm{pKa}$ $\left(\mathrm{pKa}^{+}{ }_{\mathrm{NH}}=10\right)$ [32]. Then, the electrostatic attraction between arsenic anions and protonated amino groups contributes to the adsorption, as shown in the Eqs. (3) and (4) [6]. The third pathway is the attachment of amine functional groups onto the surface of adsorbents and their replacement with oxygen groups, which is a modification method for producing strong adsorbents toward heavy metals [33]. This reaction mechanism is also consistent with XPS analysis results.

$$
\begin{aligned}
& \mathrm{SBC}-\mathrm{NH}_{3}+\mathrm{H}_{2} \mathrm{AsO}_{4}=\mathrm{SBC}-\mathrm{NH}_{3} \cdot \mathrm{H}_{2} \mathrm{AsO}_{4} \\
& \mathrm{SBC}-\mathrm{NH}_{3}+\mathrm{H}_{3} \mathrm{AsO}_{3}=\mathrm{SBC}-\mathrm{NH}_{3} \cdot \mathrm{H}_{3} \mathrm{AsO}_{3}
\end{aligned}
$$

The surface composition of the pristine and amino functionalized DETA-SBC materials was analyzed by XPS. The core level spectrum of N1s of the DETA-SBC sample reveals the binding energy peaks at 398.5, 399.6 and $400.4 \mathrm{eV}$ corresponding to $\mathrm{C}-\mathrm{NH}_{3}{ }^{+}, \mathrm{C}-\mathrm{NH}_{2}$ and C$\mathrm{N}=\mathrm{C}$ core levels, respectively. The percentages of $\mathrm{C}$ $\mathrm{NH}_{3}{ }^{+}, \mathrm{C}-\mathrm{NH}_{2}$ and $\mathrm{C}-\mathrm{N}=\mathrm{C}$ relative to the total $\mathrm{N}$ were calculated, as shown in Fig. 13. Similar types of satellite peaks were observed earlier by Ederer et al. [34]. By comparing Fig. 13a and b, it can be seen that the relative content of $\mathrm{C}-\mathrm{NH}_{3}{ }^{+}$after the reaction was reduced from 47 to 29\%; meanwhile, that of $\mathrm{C}-\mathrm{NH}_{2}{ }^{+}$increased from 23 to $60 \%$, which implied that during the adsorption experiment, the $\mathrm{C}-\mathrm{NH}_{3}{ }^{+}$groups that were coupled with the SBC were likely to react with the As anions contaminants adsorbed on the surface of the electrode particles, causing a decrease in the $\mathrm{C}-\mathrm{NH}_{3}{ }^{+}$content.

\section{Carbonization benefit assessment}

In this experiment, the amount of biomass carbon was prepared in each batch to be $300 \mathrm{~kg}$. The first, the equipment and power are listed for producing biochar adsorbent, as shown in Table 5. The second, the cost of chemicals, gases, water, electricity and personnel used for developing biochar adsorbent was calculated. After analysis and calculation, the cost of preparing biochar

Table 5 Cost of preparing biochar adsorbent

\begin{tabular}{lll}
\hline No. & Project & Cost (USD) \\
\hline 1 & Chemical fee & 1100 \\
2 & Water fee & 890 \\
3 & Electricity fee & 15 \\
4 & Labor costs & 20 \\
5 & Raw material costs (sludge) & 0 \\
The cost of preparing biochar (USD kg-1) & 6.75 \\
\hline
\end{tabular}

adsorbent is 6.75 USD kg-1. This is a considerably lower cost than industrial-specific adsorption materials.

\section{Conclusions}

These findings clearly show the feasibility of processing biochar from hospital sludge as a carbon source. The biochar has homogeneous pores and high surface area $\left(>520 \mathrm{~m}^{2} \mathrm{~g}^{-1}\right)$. The removal efficiency of As (III) and DMA significantly increases with increasing DETA content from 0.7 to $4.6 \%$. But the removal efficiency is not changed with increasing the DETA content from 4.6 to $5.9 \%$. The amino groups impregnated on SBC significantly can enhance the adsorption capacity for As (III) and DMA. The DFT results showed that both physical and chemical adsorption of As (III) and DMA on SBC surface took place. The presence of amine functional complexes greatly promoted SBC surface activity and its adsorption potential on arsenic. The reaction mechanism is divided into three pathways.

\section{Acknowledgements \\ The authors acknowledge financial supports from the Taiwan's Ministry of Science and Technology (MOST 107-2622-E-197-001 -CC3). First author ac- knowledges the Department of Environmental Engineering, National I-Lan University, Taiwan to support his research at the university.}

\section{Authors' contributions}

Chih-Kuei Chen provided real test data, Thuy-Trang Le supported the test data, Cong-Chinh Duong wrote the paper, Thi -Thanh Duong analyzed the test data, and Nhat-Thien Nguyen organized the researched full structure. All authors read and approved the final manuscript.

Funding

Not applicable.

Availability of data and materials

All data generated or analyzed during this study are examined by our group and certified for several times.

\section{Declarations}

\section{Competing interests}

The authors declare they have no competing interests.

\section{Author details}

${ }^{1}$ Department of Environmental Engineering, National I-Lan University, Ilan 26047, Taiwan. ${ }^{2}$ Continental Water Engineering Corporation, Taipei 10608 , Taiwan. ${ }^{3}$ Institute of Environmental Engineering and Management, National Taipei University of Technology, Taipei 10608, Taiwan. ${ }^{4}$ Environment and Natural Sciences, Duy Tan University, Da Nang 500000, Viet Nam. ${ }^{5}$ Southern Institute of Water Resources Research, Ho Chi Minh 700000, Vietnam.

${ }^{6}$ Faculty of Environment and Natural Resources, Ho Chi Minh City University of Technology, Ho Chi Minh 700000, Vietnam.

Received: 1 December 2020 Accepted: 8 August 2021

Published online: 07 September 2021

\section{References}

1. Giri AK, Patel R, Mandal S. Removal of $\mathrm{Cr}(\mathrm{VI})$ from aqueous solution by Eichhornia crassipes root biomass-derived activated carbon. Chem Eng J. 2012;185:71-81.

2. Tan XF, Liu SB, Liu YG, Gu YL, Zeng GM, Hua XJ, et al. Biochar as potential sustainable precursors for activated carbon production: multiple applications in environmental protection and energy storage. Bioresour Technol. 2017;227:359-72. 
3. Zhi MJ, Liu SH, Hong ZL, Wu NQ. Electrospun activated carbon nanofibers for supercapacitor electrodes. RSC Adv. 2014;4:43619-23.

4. Acikyildiz M, Gurses A, Karaca S. Preparation and characterization of activated carbon from plant wastes with chemical activation. Micropor Mesopor Mat. 2014;198:45-9.

5. Karmacharya MS, Gupta VK, Tyagi I, Agarwal S, Jha VK. Removal of As (III) and $\mathrm{As}(\mathrm{V})$ using rubber tire derived activated carbon modified with alumina composite. J Mol Liq. 2016;216:836-44.

6. Hao LL, Zheng T, Jiang JP, Zhang GS, Wang P. Removal of As (III) and As( $($ ) from water using iron doped amino functionalized sawdust: characterization, adsorptive performance and UF membrane separation. Chem Eng J. 2016;292:163-73.

7. Hamed MM, Ali MMS, Holiel M. Preparation of activated carbon from doum stone and its application on adsorption of ${ }^{60} \mathrm{Co}$ and ${ }^{152+154} \mathrm{Eu}$ : equilibrium kinetic and thermodynamic studies. J Environ Radioactiv. 2016;164:113-24.

8. Uddin MK. A review on the adsorption of heavy metals by clay minerals, with special focus on the past decade. Chem Eng J. 2017;308:438-62.

9. Ray PZ, Shipley HJ. Inorganic nano-adsorbents for the removal of heavy metals and arsenic: a review. RSC Adv. 2015:5:29885-907.

10. Mandal S, Sahu MK, Patel RK. Adsorption studies of arsenic (III) removal from water by zirconium polyacrylamide hybrid material (ZrPACM-43). Water Resour Ind. 2013;4:51-67.

11. Choong TSY, Chuah TG, Robiah Y, Koay FLG, Azni I. Arsenic toxicity, health hazards and removal techniques from water: an overview. Desalination. 2007;217:139-66

12. Mohan D, Pittman CU. Arsenic removal from water/wastewater using adsorbents - a critical review. J Hazard Mater. 2007;142:1-53.

13. Smith $\mathrm{AH}$, Lingas EO, Rahman $\mathrm{M}$. Contamination of drinking-water by arsenic in Bangladesh: a public health emergency. B World Health Organ. 2000;78:1093-103.

14. Zhang $Y$, Liu J. Density functional theory study of arsenic adsorption on the $\mathrm{Fe}_{2} \mathrm{O}_{3}$ (001) surface. Energy Fuel. 2019;33:1414-21.

15. Fan YM, Weng QY, Zhuo YQ, Dong ST, Hu PB, Li DL. Theoretical study of $\mathrm{As}_{2} \mathrm{O}_{3}$ adsorption mechanisms on $\mathrm{CaO}$ surface. Materials. 2019;12:677.

16. Gao ZY, Li MH, Sun Y, Yang WJ. Effects of oxygen functional complexes on arsenic adsorption over carbonaceous surface. J Hazard Mater. 2018:360: 436-44.

17. BIOVIA. BIOVIA Materials Studio DMoL ${ }^{3}$ Datasheet. San Diego: BIOVIA; 2018 ,

18. Perdew JP, Burke K, Ernzerhof M. Generalized gradient approximation made simple. Phys Rev Lett. 1996;77:3865-8.

19. Delley B. Hardness conserving semilocal pseudopotentials. Phys Rev B. 2002; 66:155125.

20. Hu LJ, Peng Y, Wu F, Peng SZ, Li JJ, Liu ZZ. Tubular activated carbons made from cotton stalk for dynamic adsorption of airborne toluene. J Taiwan Inst Chem E. 2017:80:399-405.

21. Wang SJ. Pore size control of MCM-41 [Master's Thesis]. Taoyuan City: National Central Univ; 2005.

22. Ma Y, Liu WJ, Zhang N, Li YS, Jiang H, Sheng GP. Polyethylenimine modified biochar adsorbent for hexavalent chromium removal from the aqueous solution. Bioresour Technol. 2014;169:403-8

23. Kilic M, Apaydin-Varol E, Putun AE. Adsorptive removal of phenol from aqueous solutions on activated carbon prepared from tobacco residues: equilibrium, kinetics and thermodynamics. J Hazard Mater. 2011;189:397-403.

24. Jindo K, Mizumoto H, Sawada Y, Sanchez-Monedero MA, Sonoki T. Physical and chemical characterization of biochars derived from different agricultural residues. Biogeosciences. 2014;11:6613-21.

25. Ma J, Zhu ZL, Chen B, Yang MX, Zhou HM, Li C, et al. One-pot, large-scale synthesis of magnetic activated carbon nanotubes and their applications for arsenic removal. J Mater Chem A. 2013;1:4662-6.

26. Chen CC, Chen CF, Chen CM, Chuang FT. Modification of multi-walled carbon nanotubes by microwave digestion method as electrocatalyst supports for direct methanol fuel cell applications. Electrochem Commun. 2007;9:159-63

27. Yang BY, Cao Y, Qi FF, Li XQ, Xu Q. Atrazine adsorption removal with nylon6/polypyrrole core-shell nanofibers mat: possible mechanism and characteristics. Nanoscale Res Lett. 2015;10:207.

28. Guo XJ, Chen FH. Removal of arsenic by bead cellulose loaded with iron oxyhydroxide from groundwater. Environ Sci Technol. 2005;39:6808-18.

29. Fu DD, He ZQ, Su SS, Xu B, Liu YL, Zhao YP. Fabrication of a-FeOOH decorated graphene oxide-carbon nanotubes aerogel and its application in adsorption of arsenic species. J Colloid Interf Sci. 2017;505:105-14.
30. Xiong Y, Tong Q, Shan WJ, Xing ZQ, Wang YJ, Wen SQ, et al. Arsenic transformation and adsorption by iron hydroxide/manganese dioxide doped straw activated carbon. Appl Surf Sci. 2017;416:618-27.

31. Nwosu FO, Olu-Owolabi Bl, Adebowale KO. Kinetics and thermodynamic adsorption of $\mathrm{Pb}$ (II) and $\mathrm{Cd}$ (II) ions from used oil onto Thevetianeriifolia nutshell active carbon. Curr Res Chem. 2012;4:26-40.

32. Dobrowolski R, Otto M. Preparation and evaluation of Ni-loaded activated carbon for enrichment of arsenic for analytical and environmental purposes. Micropor Mesopor Mat. 2013;179:1-9.

33. Deliyanni EA, Kyzas GZ, Triantafyllidis KS, Matis KA. Activated carbons for the removal of heavy metal ions: a systematic review of recent literature focused on lead and arsenic ions. Open Chem. 2015;13:699-708.

34. Ederer J, Janos P, Ecorchard P, Tolasz J, Stengl V, Benes H, et al. Determination of amino groups on functionalized graphene oxide for polyurethane nanomaterials: XPS quantitation vs. functional speciation. RSC Adv. 2017;7:12464-73.

35. Gazzari S, Cortes-Arriagada D. Interaction of trivalent arsenic on different topologies of Fe-doped graphene nanosheets at water environments: a computational study. J Mol Liq. 2019;289:111137.

36. Hou JT, Luo JL, Song SX, Li YZ, Li QZ. The remarkable effect of the coexisting arsenite and arsenate species ratios on arsenic removal by manganese oxide. Chem Eng J. 2017;315:159-66.

37. Biswas $P$, Nath $P$, Sanyal D, Banerji P. An alternative approach to investigate the origin of p-type conductivity in arsenic doped ZnO. Curr Appl Phys. 2015;15:1256-61.

38. Han J, Lee S, Choi K, Kim J, Ha D, Lee CG, et al. Effect of nitrogen doping on titanium carbonitride-derived adsorbents used for arsenic removal. J Hazard Mater. 2016;302:375-85.

39. Wei ZG, Liang K, Wu Y, Zou YD, Zuo JH, Arriagada DC, et al. The effect of $\mathrm{pH}$ on the adsorption of arsenic (III) and arsenic $(\mathrm{V})$ at the $\mathrm{TiO}_{2}$ anatase [101] surface. J Colloid Interf Sci. 2016;462:252-9.

40. Charlet L, Morin G, Rose J, Wang YH, Auffan M, Burnol A, et al. Reactivity at (nano)particle-water interfaces, redox processes, and arsenic transport in the environment. Cr Geosci. 2011;343:123-39.

41. Zhang MY, He GZ, Pan G. Structure and stability of arsenate adsorbed on a$\mathrm{Al}_{2} \mathrm{O}_{3}$ single-crystal surfaces investigated using grazing-incidence EXAFS measurement and DFT calculation. Chem Geol. 2014:389:104-9.

\section{Publisher's Note}

Springer Nature remains neutral with regard to jurisdictional claims in published maps and institutional affiliations.

Ready to submit your research? Choose BMC and benefit from:

- fast, convenient online submission

- thorough peer review by experienced researchers in your field

- rapid publication on acceptance

- support for research data, including large and complex data types

- gold Open Access which fosters wider collaboration and increased citations

- maximum visibility for your research: over $100 \mathrm{M}$ website views per year

At $\mathrm{BMC}$, research is always in progress.

Learn more biomedcentral.com/submissions 